\title{
BMJ Open COVID-19 management in nursing homes by outbreak teams (MINUTES) - study description and data characteristics: a qualitative study
}

\author{
Lisa S van Tol (D , ${ }^{1}$ Hanneke J A Smaling, ${ }^{1}$ Janneke M Groothuijse, ${ }^{1}$ \\ Arno J Doornebosch, ${ }^{1}$ Sarah I M Janus, ${ }^{2}$ Sytse U Zuidema, ${ }^{2}$ \\ Monique A A Caljouw, ${ }^{1}$ Wilco P Achterberg, ${ }^{1}$ Margot W M de Waal ${ }^{1}$
}

To cite: van Tol LS, Smaling HJA, Groothuijse JM, et al. COVID-19 management in nursing homes by outbreak teams (MINUTES) - study description and data characteristics: a qualitative study. BMJ Open 2021;11:e053235. doi:10.1136/ bmjopen-2021-053235

- Prepublication history and additional supplemental material for this paper are available online. To view these files, please visit the journal online (http://dx.doi.org/10.1136/ bmjopen-2021-053235).

Received 07 May 2021 Accepted 11 November 2021

Check for updates

(C) Author(s) (or their employer(s)) 2021. Re-use permitted under CC BY-NC. No commercial re-use. See rights and permissions. Published by BMJ.

${ }^{1}$ Public Health and Primary Care, Leiden University Medical Center, Leiden, The Netherlands ${ }^{2}$ General Practice \& Elderly Care Medicine, University Medical Center Groningen, Groningen, The Netherlands

Correspondence to

Lisa S van Tol;

I.s.van_tol@lumc.nl

\section{ABSTRACT}

Objectives Nursing homes are hit relatively hard by the COVID-19 pandemic. Dutch long-term care (LTC) organisations installed outbreak teams (OTs) to coordinate COVID-19 infection prevention and control. LTC organisations and relevant national policy organisations expressed the need to share experiences from these 0Ts that can be applied directly in COVID-19 policy. The aim of the 'COVID-19 management in nursing homes by outbreak teams' (MINUTES) study is to describe the challenges, responses and the impact of the COVID-19 pandemic in Dutch nursing homes. In this first article, we describe the MINUTES Study and present data characteristics.

Design This large-scale multicentre study has a qualitative design using manifest content analysis. The participating organisations shared their OT minutes and other meeting documents on a weekly basis. Data from week 16 (April) to week 53 (December) 2020 included the first two waves of COVID-19.

Setting National study with 41 large Dutch LTC organisations.

Participants The LTC organisations represented 563 nursing home locations and almost 43000 residents. Results At least 36 of the 41 organisations had one or more SARS-CoV-2 infections among their residents. Most OTs were composed of management, medical staff, support services staff, policy advisors and communication specialists. Topics that emerged from the documents were: crisis management, isolation of residents, personal protective equipment and hygiene, staff, residents' wellbeing, visitor policies, testing and vaccination.

Conclusions OT meeting minutes are a valuable data source to monitor the impact of and responses to COVID-19 in nursing homes. Depending on the course of the COVID-19 pandemic, data collection and analysis will continue until November 2021. The results are used directly in national and organisational COVID-19 policy.

\section{INTRODUCTION}

COVID-19 can have a serious and fatal course, especially among vulnerable older adults. ${ }^{12}$ Thus, nursing homes were hit relatively hard by the pandemic. In 2020, nursing home residents in many countries made up substantial
Strengths and limitations of this study

- Minutes of outbreak teams capture the impact, challenges and responses to problems and measures taken regarding the COVID-19 pandemic in longterm care organisations. However, some minutes were only brief descriptions of decisions that lacked context.

- Collecting existing minutes enabled analysis of a large amount of data, without adding to staff burden, that is often not feasible in qualitative studies.

- Minutes data allow not only for in-depth scientific analyses but can also directly be used as input for national and organisational COVID-19 policies.

- The longitudinal nature of our study enables analysis of medium and long-term impact of the pandemic in nursing homes during multiple waves of infections over time.

proportions of COVID-19-related deaths. ${ }^{3}$ Besides, COVID-19-related measures negatively impact nursing home residents' mental and physical well-being. ${ }^{4}$

Prior to the COVID-19 pandemic, nursing homes and other long-term care facilities (LTCFs) have had ample experience with outbreaks such as norovirus and influenza. Guidelines are available on how to prevent and act in case of outbreaks of these infectious diseases. ${ }^{5}$ By contrast, COVID-19 was unknown, and the impact of the pandemic required rapid policy decisions. For example, social distancing, wearing face masks and avoiding crowds became important policies to slow the spread of the virus. ${ }^{6}$ LTCFs in many European countries were also faced with visitor bans. ${ }^{7}$

To implement policies regarding infection prevention and control (IPC), the WHO recommends LTCFs to have an IPC focal point to lead and coordinate IPC activities, 
supported by an IPC team. ${ }^{8}$ They would be responsible for IPC training, providing information to residents, maintaining high hygiene standards and more. ${ }^{8}$ Most Dutch LTC organisations have an IPC committee, but in severe outbreaks such as COVID-19, these organisations install or convert IPC committees into outbreak teams (OTs). In contrast to IPC committees, OTs include management representatives. $^{9}$

Both LTC organisations and national policy institutes, including the Ministry of Public Health Welfare and Sport, expressed the need to learn from each other by sharing experiences, which could be used directly in LTC COVID-19 policy considerations. Therefore, the aim of the 'COVID-19 management in nursing homes by outbreak teams' (MINUTES) study was to describe the challenges presented by, responses to, and the impact of the COVID-19 pandemic in nursing homes, based on the minutes and other meeting documents of the OTs. We will describe the MINUTES Study and present data characteristics and topics discussed by the OTs.

\section{METHODS}

\section{Study design and setting}

The MINUTES Study is a large, national multicentre study and has a qualitative design based on manifest content analysis of meeting documents. OTs document their meetings in minutes. In order to avoid adding to staff burden during this crisis, we have collected and analysed these minutes. Directors of all LTC organisations informed their OTs about study participation and provided written informed consent.

Dutch LTC organisations often provide a wide range of inpatient and outpatient medical and social care. ${ }^{10}$ In nursing homes, care is provided by multidisciplinary teams, coordinated by specially trained and registered elderly care physicians. ${ }^{11} 12$ Inpatient-assisted living care is provided in care homes. ${ }^{10}$ Furthermore, many LTC organisations provide geriatric rehabilitation and homecare. ${ }^{10}$ The focus of this study is on care homes and nursing homes, hereafter referred to as nursing homes.

In 2020, about 8000 to 13000 of the total 115000 nursing home residents nationwide ${ }^{13}$ had a confirmed SARS-CoV-2 infection. More than 2300 COVID-19-related deaths were registered. ${ }^{14}$ National infection rates in the Netherlands showed a 'first wave' from weeks 11 to 19 of 2020 and a 'second wave' from week 39 onwards. ${ }^{15}$

\section{Participants}

The LTC organisations of the Dutch academic nursing home research networks ${ }^{16}$ were approached for participation by email in weeks $11-15$ of 2020 . The aim was to recruit at least $50 \%$ of the organisations from at least two networks to achieve an accurate reflection of the actual situation. Other LTC organisations that heard of the study and expressed a willingness to participate were also eligible for participation. The meeting documents had to include minutes, preferably supplemented with associated meeting documents, such as overviews of SARS-CoV-2 infections among residents.

\section{Data collection}

OT meeting documents were shared with the study institute's research centre within a week after the meetings. The research centre operated as trusted third party; they pseudonymised names of LTC organisations and deleted personal data of residents and staff from the submitted documents. Subsequently, they uploaded the documents in the online electronic data capture program 'Castor',17 to make them available to the researchers for analysis. In addition, the organisations were asked to provide numbers of residents, employees, nursing home locations, as well as organisation and OT characteristics.

\section{Data analysis}

A coding frame was developed inductively by two coordinating researchers (LSvT, MWMdW). They independently coded the same minutes document in order to develop a first version of the coding frame. Subsequently, from weeks 12 to 15 , they each coded half of the documents that were available from the first six participating LTC organisations with this first version of the coding frame. In weekly consensus meetings, they discussed their work and expanded the coding frame (online supplemental appendix). After week 15, all other researchers could suggest additional codes. Which of the suggested codes were added to the coding frame was decided by three coordinating researchers (LSvT, MWMdW, JMG).

In total, 19 researchers analysed the meeting documents, ranging from master students and $\mathrm{PhD}$ candidates to post-doc researchers. The common denominator was that they all performed research with a focus on LTC and wanted to assist in the pandemic.

Data were analysed using manifest content analysis. ${ }^{18} 19$ This was done on a weekly basis in two steps. First, the researchers coded the meeting documents. They were instructed to select at least all passages, called textual units, that included data on measures, problems, stock or infection rates. This corresponds with the study aim to describe the challenges (problems, stock, infections rates) presented by, responses to (measures) and the impact of (resulting from challenges and responses) the COVID-19 pandemic in nursing homes. Besides, the researchers were aware of the use of data for writing the summary reports described below as input for policy. Each textual unit selected had to be assigned with a code from the coding frame in an open field in the Castor database. Second, the coordinating researchers clustered codes into topics, which are referred to as 'data categories' in literature. $^{19}$

\section{Quality control}

The coordinating researchers provided all other researchers individually with instructions, digital standard operating procedures and the coding frame. For each researcher, the textual units they selected in their 
first 2-4 weeks were double coded by LSvT and if needed, feedback was given and improvement was monitored. Half yearly meetings with all researchers were organised. Besides, all coded data were checked by one of two coordinating researchers (LSvT or JMG) on a weekly basis.

\section{Summary reports}

Besides scientific analysis, coded data were used by the coordinating researchers to prepare summary reports on a weekly to triweekly basis. In these reports, they summarised the most recent meeting documents and listed what they regarded as the most important points of attention for policymakers. These reports were shared as input for policy with participating LTC organisations, the Ministry of Public Health, Welfare and Sport, the chief nursing officer, and professional associations for elderly care physicians, nurses, and nursing homes.

\section{Patient and public involvement}

This study was initiated based on the need of LTC organisations and national policy organisations to share experiences from OTs that can be applied directly in COVID-19 policy. The study did not involve patients and the public in study design or analyses. However, we frequently held evaluation meetings with the receivers of the summary reports for feedback and additional research questions. In a follow-up study, nursing home staff has elaborated on OTs' responses to the pandemic that were described in the meeting documents.

\section{RESULTS}

The data characteristics presented in this article are based on the data from week 16 to week 53, 2020, including the first two waves of COVID-19 infections.

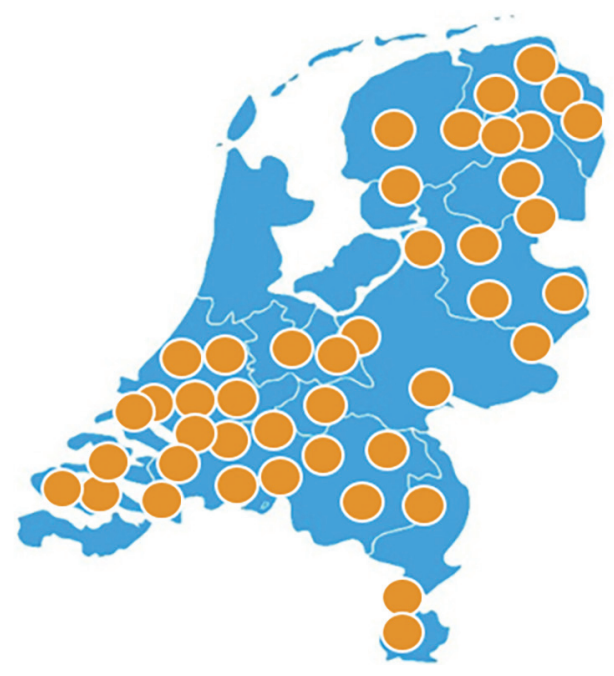

Figure 1 Participating long-term care (LTC) organisations from the Netherlands. *Two LTC organisations with locations in multiple regions are presented with multiple dots
Table 1 Description of participating long-term care organisations

\begin{tabular}{|c|c|}
\hline Participating organisations & $n=41(100 \%)$ \\
\hline & Range/no (\%) \\
\hline Nursing home locations & $3-70$ \\
\hline $1-10$ & $20(49)$ \\
\hline $11-20$ & $17(42)$ \\
\hline$\geq 20$ & $4(10)$ \\
\hline Residents & $171-4700$ \\
\hline $1-999$ & $20(49)$ \\
\hline $1000-1999$ & $14(34)$ \\
\hline$\geq 2000$ & $5(12)$ \\
\hline Missing & $2(5)$ \\
\hline \multicolumn{2}{|l|}{ SARS-CoV-2-infected residents } \\
\hline Yes & $36(88)$ \\
\hline Missing & $5(12)$ \\
\hline Week 16-19 & $22(54)$ \\
\hline Week 20-38 & $9(22)$ \\
\hline Week 39-53 & $29(71)$ \\
\hline Start date OT & Week 8-13 \\
\hline$\leq$ Week 9 & $3(7)$ \\
\hline Week 10-11 & $17(42)$ \\
\hline$\geq$ Week 12 & $7(17)$ \\
\hline Missing & $14(34)$ \\
\hline Data shared in weeks & Median (IQR) \\
\hline Week 16-53 (38 weeks) & $24(10.5-35.0)$ \\
\hline
\end{tabular}

OT, outbreak team.

\section{Participating LTC organisations}

A total of 41 LTC organisations participated in this study (figure 1). These organisations represented almost 43000 residents living in 563 nursing home locations. Of these 41 organisations, 39 belonged to five of the six Dutch academic nursing home research networks, representing $58 \%$ of the organisations in these networks. The organisations varied in size from 3 to 70 nursing homes. More than $40 \%$ of the organisations installed their OTs in week 10 or 11 . From weeks 16 to 53 , at least $88 \%(n=36)$ of the organisations had (one or more) SARS-CoV-2 infections among residents (table 1). Organisations, on average, shared meeting documents over 23.1 of 38 weeks (median 24, IQR 10.5-35.0). Per week, 15 (week 32) to 39 (week 18) organisations shared meeting documents (figure 2). Five organisations contributed meeting documents over all 38 weeks.

\section{OTs' members}

The composition of the OT was known for 30 LTC organisations $(73 \%)$. All but one included management (eg, directors, managers and administrators). In $60 \%-80 \%$ of the OTs, medical staff (eg, elderly care physicians, occupational physicians and other physicians), support services 


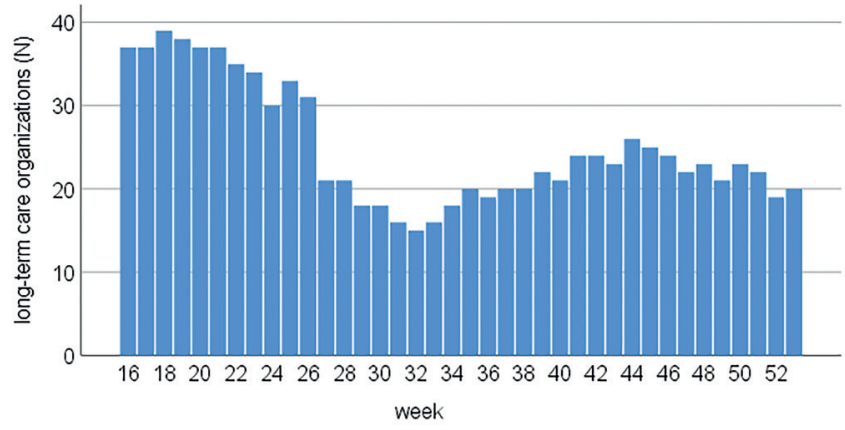

Figure 2 Number of long-term care organisations that shared meeting documents per week.

staff (facility management and human resources), policy advisors (including quality officers) and communication specialists were represented. In a few OTs, nursing staff (six OTs) and residents (one OT) were represented (figure 3).

\section{Qualitative topics}

The following eight topics were extracted from the data. Matching quotes that illustrate these topics are presented in box 1 .

\section{Crisis management}

From the start of the pandemic, OTs discussed infection rates, COVID-19-related finances, OT meeting frequency, internal and external communication, and regional collaboration. Besides, OTs prepared for worst-case scenarios and monitored and evaluated IPC and outbreak management. For example, OT meeting frequencies depended on infection rates.

\section{Isolation of residents}

The occupation and availability of beds for both SARSCoV-2-infected and non-infected residents and other SARS-CoV-2-infected patients was a recurring topic. LTC organisations applied various isolation and social distancing policies, such as quarantine, isolation in single rooms and cohort isolation. Besides, at various times, nursing home departments stopped admitting new residents or providers of 'non-essential' care, such as hairdressers and dental hygienists. OTs also discussed ethical dilemmas and customisation of these measures to local

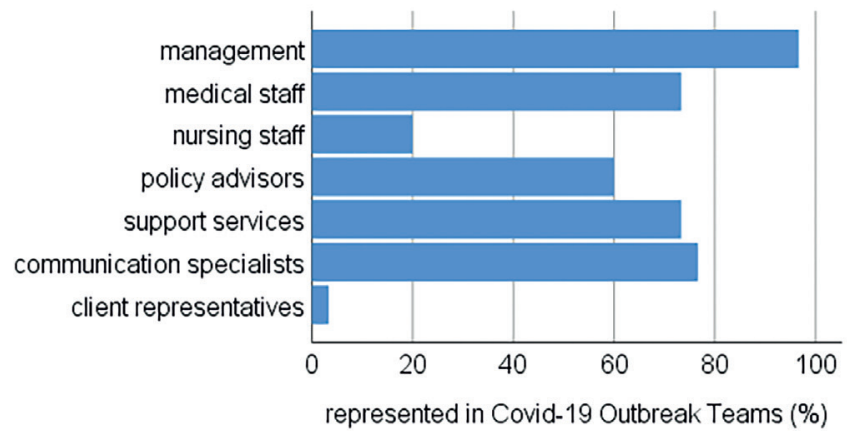

Figure 3 Disciplines represented in outbreak teams.
Box 1 Quotes from meeting documents illustrating the topics identified

Crisis management

'Roadmaps (description of operational [0T] with clear roles) for new infections.' (organisation XF, week 26)

'A next [0T] meeting will not yet be scheduled, but the situation in [municipality] will be monitored.' (organisation YF, week 33)

'It is unclear how financing the COVID-wards in the province is going.' (organisation YX, week 23)

\section{Isolation of residents}

'Scenario positive resident: no transferring, isolation in own room/ ward-otherwise to cohort ward.' (organisation YB, week 25)

'Hair dressers and beauticians can't go back to work yet in the nursing homes, because these homes are still locked down. The medical pedicure [podiatrist] can come and treat indoors on doctor's prescription.' (organisation XT, week 20)

'Residents with psychogeriatric problems and the urge to wander are difficult to keep in quarantine for 7 days. They are therefore not admitted to [location], which is still 'clean'.' (organisation XZ, week 16)

\section{PPE and hygiene}

'Pressure is put on ordering the right aprons, these are hard to get.' (organisation XF, week 16)

'At psychogeriatrics [ward] it has been indicated that continuously working with mouth mask/PPE is not always experienced positively by residents and staff. Yet with ADL care [care regarding activities of daily living], PPE's are experienced as pleasant.' (organisation YS, week 31)

'Attend staff to sound hand hygiene and sound use of gloves. Keep cleaning laptops, telephones, door handles etc.' (organisation YW, week 41)

\section{Staff}

'The exchange of staff between [ward] and other parts of [nursing home] has to be prevented as much as possible.' (organisation XH, week 20) 'We could fall back on the old scenario, like asking retired nurses and call in the military. Getting regional assistance will be difficult.' (organisation XF, week 41)

'In ward with many infections the workload is high, staff members are emotionally 'done'.' (organisation YB, week 18)

\section{Residents' well-being}

'Due to a positive [tested] residents, the other residents feel restless and would like to leave their rooms.' (organisation XF, week 21)

'Church activities with 1.5 meters distance, maximum 30 persons, singing discouraged.' (organisation XS, week 24)

\section{Visitor policies}

'Volunteers are deployed for visitors cabins: scheduling appointments, receiving visitors, serving coffee, cleaning cabin after each visit.' (organisation XZ, week 17)

'Family does not keep enough distance from the residents. Staff finds this worrisome, visitors don't allow anyone to correct them. The question remains what can be done about this.' (organisation XH, week 27)

\section{Testing}

'If a resident tests positive, we will test the fellow residents and close contacts of the residents with rapid tests.' (organisation YE, week 46) 'Not enough test materials in stock available. Swaps have to be picked up and brought back again.' (organisation XC, week 43)

'Because healthcare workers sometimes cannot be tested within 24 hours, our own test location is being set up.' (organisation XF, week 36)

Continued 


\section{Box 1 Continued}

\section{Vaccination}

'Preparing vaccinating, the [IPC committee] believes that it is too early to set up a program/plan. A message with information about how a vaccine works is already being placed on the intranet.' (XP week 52) IPC, infection prevention and control; OT, outbreak team; PPE, personal protective equipment.

situations or resident groups, for example, residents with psychogeriatric problems.

\section{Personal protective equipment and hygiene}

This topic included hygiene procedures, and available stock, policies for use, and experiences with wearing personal protective equipment (PPE). With shortages and rising costs, OTs considered the sterilisation and reuse of PPE. Besides, OTs discussed promoting proper PPE use and set policies for what types of PPE and when to be used by which staff members. Changes in national guidelines gave cause for discussion. Hygiene procedures included hand hygiene, laundry and waste management, and airborne precautions such as use of air conditioning and ventilation.

\section{Staff}

This topic included isolation and social distancing restrictions for staff, workforce scheduling, supporting staff with materials and facilities, their well-being and mental support. The minutes first described distancing policies for employees and volunteers during work, training sessions and meetings, for example, staff members were not allowed to work in more than one nursing home location. In addition, isolation measures and absenteeism were topics of conversation. Staff waiting for their own or their housemates' test results had to stay at home in quarantine or, in times of staff shortages, had to work in COVID-19 cohorts. Second, workforce scheduling was a logistical challenge due to high absenteeism among staff and distancing policies. Therefore, temporary workers, non-healthcare staff members and army medical staff were deployed. Third, OTs facilitated staff by means of equipment to work from home. Fourth, OTs discussed the impact of the COVID-19 crisis on staff mental wellbeing. They spoke of emotional exhaustion of staff due to the high workload, fear of becoming infected and verbal abuse by residents' family members. LTC organisations set up various mental support initiatives to support staff.

\section{Residents' well-being}

A few times the observed impact of the COVID-19 crisis on residents' well-being was mentioned, for example, increased loneliness and restlessness. OTs discussed restarting or continuation of activities for residents. Group activities had to be replaced by individual or living room activities. Issues also included whether to allow residents to go outside with their informal caregivers.
Palliative care, death rituals and memorial events required adjusting.

\section{Visitor policies}

This topic is about the organisation of and experiences with visiting policies. During total lockdowns, alternatives for social contact were offered, such as window visits and video calling. After the national visitor ban was partly lifted in May, OTs made decisions about regulated lengths of visits, maximum numbers of visitors and use of PPE by visitors. To organise these policies, visitors needed to register upon entering the nursing home or had to schedule their visit online. Sometimes LTC organisations allowed staff to customise visiting policies to local situations or for residents in the end-of-life phase. OTs discussed experiences with and impact of these policies and considered how to deal with family of residents who disagreed with visiting policies.

\section{Testing}

Since week 15, when testing of nursing home staff and residents for COVID-19 became possible nationwide, OTs discussed the policies, organisation and logistics of testing. Many LTC organisations implemented a policy to test residents at nursing home admission. In some organisations, staff and residents without symptoms were preventively tested following contact with an infected person. Regarding organisation and logistics, routes for requesting tests and receiving test results required OTs' attention. Several organisations arranged their own testing facilities, due to waiting times at governmental test facilities.

\section{Vaccination}

The topic of vaccination for residents and staff emerged around week 49. Staff and residents had to be informed about the upcoming vaccination process and preparations for vaccination had to be made.

\section{DISCUSSION}

The COVID-19 MINUTES Study describes the challenges presented by, responses to and the impact of the COVID-19 pandemic in Dutch nursing homes. The representative sample of 41 LTC organisations all installed OTs in weeks 8-13. The composition of OTs was multidisciplinary. Almost all organisations had SARS-CoV-2 infections among nursing home residents. Topics in the qualitative data included crisis management, isolation of residents, PPE and hygiene, staff, residents' well-being, visitor policies, testing and vaccination.

To our knowledge, the COVID-19 MINUTES Study is the first large-scale qualitative study examining the challenges, responses and the impact of the COVID-19 pandemic in nursing homes. In forthcoming studies, more in-depth analyses of the topics observed here will provide information that will be useful for management 
and IPC in subsequent phases of the COVID-19 pandemic and beyond.

The fluctuation in the amount of data collected per week (see figure 2) appears to reflect the fluctuation in national infection rates. ${ }^{20}$ However, compared with infection rates, the second peak in data collection seen in autumn is lower than the first peak in spring. This illustrates that the frequency of OT meetings decreased, because they learnt from the first wave. On the other hand, implementation and adaptation to changes in national guidelines to local settings continued to be the topic of conversation.

Our findings show that, in accordance with (inter) national recommendations, OTs were multidisciplinary. ${ }^{21}{ }^{22}$ However, nursing staff was represented in only one-fifth of the OTs, although it is possible that they were consulted. Nevertheless, literature recommends consultation of LTC workers or representation of nurse specialists. ${ }^{21} 22$ Besides, paramedics working in nursing homes such as physiotherapists, psychologists and social workers $^{23}$ were not represented in OTs. This underrepresentation of nursing staff and paramedics in OTs may have affected the topics discussed.

The observed topics are in line with IPC guidance literature. Apart from vaccination, all topics are mentioned by the WHO in a guidance report on COVID-19 in healthcare $^{24}$ and in a policy brief on preventing and managing COVID-19 in LTC. ${ }^{25}$ Testing, isolation of residents, PPE, and staff and residents' well-being were identified as challenges and dilemmas related to COVID-19 in care homes. ${ }^{26}$ Remarkably, ample research has shown that COVID-19-related measures negatively impact nursing home residents' mental and physical well-being, ${ }^{4}$ but only little has been described about this in the meeting documents. Apparently, either OT meetings have a different focus, or OTs discuss well-being of residents but regard this as context to decisions that does not have to be written down in the minutes.

\section{Strengths and limitations}

The first strength of our study is our data source. Minutes and other meeting documents capture challenges, responses and impact of the COVID-19 pandemic in LTC organisations. Collecting the existing documents enabled analysis of a large amount of data that is often not feasible in qualitative studies; the sample of participating LTC organisations represents over one-third of nursing home residents nationwide. ${ }^{13}$ The participating organisations indicate that the use of this data source led to a low study load during these times of crisis.

Second, the data allow for a more in-depth scientific analyses, and can also directly be used as input for national and organisational COVID-19 policies. There are other projects that supported LTC organisations during the pandemic, ${ }^{27}$ but to our knowledge, COVID-19 MINUTES is the only study that supports both organisations and national policymakers with quick input.
Third, the longitudinal nature of our study collected from the start of the COVID-19 pandemic enables analysis of medium and long-term impact of the pandemic in nursing homes. ${ }^{28}$

Some study limitations should also be recognised. First, some data were missing. Five LTC organisations did not share data on infection rates. In addition, most organisations did not share meeting minutes over the whole study period (38 weeks). However, sometimes meeting documents were absent because OTs had not held meetings, especially from weeks 20 to 38 when infection rates were low. In this regard, the amount of data that were shared is satisfactory. Moreover, the overall large amount of data available will be sufficient to reach saturation in future in-depth analyses.

Second, data sometimes lacked context, because meeting documents itself were sometimes only brief descriptions of decisions. To overcome this limitation, each researcher analysed a fixed set of LTC organisations in order to get a better indication of the context. Moreover, by selecting textual units for coding, these units are removed from their context. This is a known limitation of content analysis. $^{19}$

Third, the focus on not only scientific analyses but also on writing summary reports as input for organisational and national policymakers could have biased data coding. Possibly, the researchers mainly coded data that they considered relevant for policymaking. However, researchers were instructed to code all textual units that included data on measures, problems, stock and infection rates.

\section{Implications and future research}

Minutes and other meeting documents provide a valuable data source for studies on IPC and crisis management, without burdening staff with data collection. They can be used directly as input for national and organisational policy and scientific evaluation. Multidisciplinary OTs discussed crisis management, isolation of residents, PPE and hygiene, staff, residents' well-being, visitor policies, testing and vaccination during their meetings. Depending on the course of the COVID-19 pandemic, the data collection will continue until November 2021.

In coming studies, data over the complete study period will be analysed and challenges, responses and impact of the COVID-19 pandemic regarding the various topics will be analysed in depth. This will provide valuable lessons that can be used for management and IPC in subsequent phases of the pandemic, future heavy-impact epidemics, and other crisis situations, as healthcare organisations, national governments and (inter)national institutes will continue to innovate care.

Acknowledgements The authors thank the LUMC-PHEG research centre for their contributions to data management: Yothers, BD, van Deursen, $\mathrm{N}$ and Wesdorp, $\mathrm{N}$. Moreover, we thank all researchers that contributed to data analysis: Bruijsten, C, van Dam, PH, van Dijk, ML, Dogan, Z, Duijvekam, I, van der Kloet, H, LesmanLeegte, GHT, Meester, W, Nieuwenhuys, CMA, den Oude, A, Plomp, AM, Schepen, Y, Visser, $\mathrm{M}$ and van der Velde-van Buuringen, $\mathrm{M}$. 
Contributors LSvT, HJAS, SZ, MAAC, WPA and MWMdW initiated the study and drafted the manuscript. AJD and JMG contributed to design, maintenance and data management. SIMJ contributed to data. LSvT, HJAS, JMG, SIMJ, MWMdW and the other researchers mentioned in the acknowledgements analysed the data. All authors revised the manuscript and approved the final version to be published. LSvT accepts responsibility for the overall content as guarantor.

Funding This work was supported by the Dutch Ministry of Public Health Welfare and Sport (grant number 330526), the University Network for the Care Sector South Holland (UNC-ZH) and the University Network of Elderly Care Organizations of the University Medical Center Groningen (UNO-UMCG).

Map disclaimer The inclusion of any map (including the depiction of any boundaries therein), or of any geographic or locational reference, does not imply the expression of any opinion whatsoever on the part of BMJ concerning the legal status of any country, territory, jurisdiction or area or of its authorities. Any such expression remains solely that of the relevant source and is not endorsed by BMJ. Maps are provided without any warranty of any kind, either express or implied.

Competing interests None declared.

Patient consent for publication Not required.

Ethics approval The Leiden-The Hague-Delft Medical Ethical Committee reviewed the study protocol and provided a waiver of medical ethical approval since the study is not subject to the Dutch Medical Research Involving Human Subjects Act (WM0).

Provenance and peer review Not commissioned; externally peer reviewed.

Data availability statement Data are available upon reasonable request. During the consent process, participating organisations were explicitly guaranteed that the data would be pseudonymised by the study's research centre and that pseudonymised data would only be seen by members of the study team. For any discussions about the dataset, please contact UNC-ZH@lumc.nl.

Supplemental material This content has been supplied by the author(s). It has not been vetted by BMJ Publishing Group Limited (BMJ) and may not have been peer-reviewed. Any opinions or recommendations discussed are solely those of the author(s) and are not endorsed by BMJ. BMJ disclaims all liability and responsibility arising from any reliance placed on the content. Where the content includes any translated material, BMJ does not warrant the accuracy and reliability of the translations (including but not limited to local regulations, clinical guidelines, terminology, drug names and drug dosages), and is not responsible for any error and/or omissions arising from translation and adaptation or otherwise.

Open access This is an open access article distributed in accordance with the Creative Commons Attribution Non Commercial (CC BY-NC 4.0) license, which permits others to distribute, remix, adapt, build upon this work non-commercially, and license their derivative works on different terms, provided the original work is properly cited, appropriate credit is given, any changes made indicated, and the use is non-commercial. See: http://creativecommons.org/licenses/by-nc/4.0/.

ORCID iD

Lisa S van Tol http://orcid.org/0000-0002-9334-9214

\section{REFERENCES}

1 Wu Z, McGoogan JM. Characteristics of and Important Lessons From the Coronavirus Disease 2019 (COVID-19) Outbreak in China: Summary of a Report of 72314 Cases From the Chinese Center for Disease Control and Prevention. JAMA 2020;323:1239-42.

2 CDC COVID-19 Response Team. Severe Outcomes Among Patients with Coronavirus Disease 2019 (COVID-19) - United States, February 12-March 16, 2020. MMWR Morb Mortal Wkly Rep 2020;69:343-6.

3 Comas-Herrera A, Zalakaín J, Lemmon E. Mortality associated with COVID-19 in care homes: international evidence: international long term care policy network, 2020

4 Paananen J, Rannikko J, Harju M, et al. The impact of Covid-19related distancing on the well-being of nursing home residents and their family members: a qualitative study. Int J Nurs Stud Adv 2021;3:100031.

5 Centers for Disease Control and Prevention. Guidelines \& Guidance Library, 2020. Available: https://www.cdc.gov/infectioncontrol/ guidelines/index.html [Accessed 12 Feb 2021].

6 Centers for Disease Control and Prevention. Things to know about the COVID-19 pandemic, 2021. Available: https://www.cdc.gov/ coronavirus/2019-ncov/your-health/need-to-know.html [Accessed 12 Feb 2021].

7 Verbeek H, Gerritsen DL, Backhaus R, et al. Allowing visitors back in the nursing home during the COVID-19 crisis: a Dutch national study into first experiences and impact on well-being. J Am Med Dir Assoc 2020;21:900-4

8 World Health Organization. Infection prevention and control guidance for long-term care facilities in the context of COVID-19. World Health Organization, 2020.

9 JMGA S, Poot EP NMN, et al. Dealing with Covid-19 in Dutch nursing homes. The Journal of Nursing Home Research Sciences 2020;6:30-4.

10 Ministry of Public Health, Welfare and Sport. Healthcare in the Netherlands, 2016.

11 Koopmans RTCM, Lavrijsen JCM, Hoek JF, et al. Dutch elderly care physician: a new generation of nursing home physician specialists. $J$ Am Geriatr Soc 2010;58:1807-9.

12 Achterberg WP CM, Husebo BS. Towards academic nursing home medicine: a Dutch example for Norway? Omsorg 2015;1:70-5.

13 CBS. Aantal bewoners van verzorgings- en verpleeghuizen 2019, 2020. Available: https://www.cbs.nl/nl-nl/maatwerk/2020/13/aantalbewoners-van-verzorgings-en-verpleeghuizen-2019 [Accessed 12 Feb 2021].

14 VerenSo. Update registratie verpleeghuizen 29 December 2020 - Blijvende toename van nieuwe besmettingen in verpleeghuiz, 2020. Available: https://www.verenso.nl/nieuws/update-registratieverpleeghuizen-29-december-2020-blijvende-toename-van-nieuwebesmettingen-in-verpleeghuizen [Accessed 12 Feb 2021].

15 CBS. The year of coronavirus, 2020. Available: https://www.cbs. nl/en-gb/news/2020/53/the-year-of-coronavirus [Accessed 01 Mar 2021].

16 SANO samenwerkende academische netwerken ouderenzorg. Available: https://academischeouderenzorg.nl/ [Accessed 19 Mar 2021].

17 Castor. Available: https://www.castoredc.com/

18 Graneheim UH, Lundman B. Qualitative content analysis in nursing research: concepts, procedures and measures to achieve trustworthiness. Nurse Educ Today 2004;24:105-12.

19 Vaismoradi M, Turunen H, Bondas T. Content analysis and thematic analysis: implications for conducting a qualitative descriptive study. Nurs Health Sci 2013;15:398-405.

20 Kruse FM, van Tol LS, Vrinzen C, et al. The impact of COVID-19 on long-term care in the Netherlands: the second wave.: LTCcovid, International long-term care policy network 2020.

21 European Centre for Disease Prevention and Control. Infection prevention and control and preparedness for COVID-19 in healthcare settings fifth update -6 October 2020. Stockholm, 2020.

22 BED' PEHA. Deel 1: Draaiboek Covid 19 verpleeghuizen versie 2; 8 April 2020: Vilans, 2020: 6.

23 Schols JMGA. Nursing home medicine in the Netherlands. Eur J Gen Pract 2005;11:141-3.

24 World Health Organization. Infection prevention and control during health care when coronavirus disease (COVID-19) is suspected or confirmed interim guidance, 2020.

25 World Health Organization. Preventing and managing COVID-19 across long-term care services : policy brief. Geneva: World Health Organization, 2020.

26 Gordon AL, Goodman C, Achterberg W, et al. Commentary: COVID in care homes-challenges and dilemmas in healthcare delivery. Age Ageing 2020;49:701-5.

27 Rolland Y, Benetos A, Villars $\mathrm{H}$, et al. Editorial: a COVID-19 support platform for long term care facilities. $J$ Nutr Health Aging 2020;24:461-2.

28 van Boekel LC, Stoop A, Luijkx KG. Uitbraak COVID-19 in de verpleeghuiszorg WAT kunnen we leren uit de literatuur van andere rampen of crisissituaties? Tijdschrift voor Gerontologie en Geriatrie 2020;51. 